\title{
Is there Effect of Intervertebral Disc Herniation on the Lumbar Spine in Early Period? A Morphometric and Stereological Study
}

\author{
¿Existe Algún Efecto de la Hernia de Disco Intervertebral en la Columna \\ Lumbar en el Período Temprano? Un Estudio Morfométrico Y Estereológico
}

Vaner Köksal $^{1}$; Seda Avnioglu² \& Emre Atay ${ }^{3}$

KÖKSAL, V.; AVNIOGLU, S. \& ATAY, E. Is there effect of intervertebral disc herniation on the lumbar spine in early period? A morphometric and stereological study. Int. J. Morphol., 38(2):374-381, 2020.

SUMMARY: The degeneration of the Lumbar Intervertebral Disc (LIVD) and the other elements of the spine are an inevitable result of aging. However, it is observed that the same degree of degenerative change does not occur in each individual. In the present study, the purpose was to compare the morphometric changes on the lumbar spine with or without intervertebral disc herniation in early period. Group 1 (the Patient Group) consisted of the patients who were diagnosed with lumbar intervertebral disc hernia and who were not operated at least one month clinical duration. Group 2 (the Control Group) consisted of individuals who were selected randomly, had only back pain, underwent magnetic resonance imaging (MRI), and were determined to have intact intervertebral disc. The sagittal and axial MRI sections of lumbar spine was used for measurements and statistical evaluation. There were no statistically significant differences between the intervertebral disc volumes, vertebral body volumes and intervertebral disc anterior and posterior heights of Group 1 and 2 ( $>0.05$ ). In terms of anterior-posterior length, the length of the L5 vertebral body was determined to be more in the Patient Group $(\mathrm{p}<0.05)$. A correlation was determined in terms of the increase in L2, L4 and L5 volumes with increasing age; however, there were no statistically significant correlations between age increase and a decrease in the intervertebral disc volumes. There were no correlations between the increase in age and the decrease in intervertebral disc heights $(\mathrm{p}>0.05)$. There were no apparent relations between the change on the lumbar vertebra corpus and intervertebral disc in early period. It was concluded that the intact intervertebral disc could protect the lower lumbar vertebra corpus from degenerative changes. Although the herniation of the intervertebral disc is newly formed, it is understood that the physiological process or morphometric changes started earlier.

KEY WORDS: Aging; Back pain; Degeneration; Intravertebral Disc; Lumbar; Morphometry; Stereology; Vertebral body.

\section{INTRODUCTION}

Low back pain is one of the most frequently observed symptoms in the human musculoskeletal system. The frequency of low back pain increases with age and its frequency in the adult population is reported to vary between 60 and $90 \%$ (Altinel et al., 2008). Besides, lumbar disc herniation is one of the most common spinal degenerative disorders which may lead to Low Back Pain (LBP). The vertebral column has the physiological curve called the Regional Lordosis in the lumbar region to absorb the load on the sagittal plane. Environmental factors and regional back pain of individuals cause this physiological curve (lordosis) to deteriorate in time (Kim et al., 2006). The area where most degenerative changes in the body occur during human life is the lumbar spine (James et al., 2019; Wang et al., 2019). For this reason, today, lower back pain is one of the most common reasons of pain in society; and the annual treatment costs exceed millions of dollars in the United States (Blanchette et al., 2016; Maher et al., 2017).

In our country, lifetime prevalence goes up to $50 \%$ in urban areas, and $80 \%$ in rural areas. In addition, lower back pain is an important public health problem, which increases with aging population; and it is also the 2 nd most common cause of admission to hospitals, the 5th most common cause of hospitalization in health institutions, and the 3rd most common cause of diseases treated with surgery (Altinel et

\footnotetext{
${ }^{1}$ University of Health Sciences-Samsun Health Practices and Research Center, Department of Neurosurgery, Samsun, Turkey. Orcid No: 0000-00024902-5298.

${ }^{2}$ Alanya Alaadidn Keykubat University, Medical Faculty, Department of Anatomy, Alanya / Antalya, Turkey.

${ }^{3}$ Afyonkarahisar Health Sciences University, Medical Faculty, Department of Anatomy, Afyonkarahisar, Turkey.
} 
al.). Studies conducted on the causes affecting health or degeneration of the lumbar spine are still continuing. It is seen that studies in the literature mostly focus on Intervertebral Disc Degeneration (IVDD) (Barrera et al., 2001; Gocmen-Mas et al., 2010; Atta-Alla et al., 2014; James et al.; Wang et al., 2019). Nowadays, the conclusion is that IVDD is an inevitable consequence of life. However, it is observed that degenerative changes are not observed at the same levels even in individuals of the same age (James et $a l$.). In the literature, there are very few morphometric studies that are conducted with the measurements obtained with MR images of individuals in terms of IVDD changes (Wang et al., 2015; Azu et al., 2016). In the present study of ours, the changes in the lumbar spine elements were examined by making morphometric and stereological measurements in the Patient Group that was diagnosed with lumbar intervertebral disc hernia and that were scheduled for surgery but did not undergo surgeries (deteriorated intervertebral disc), and in another patient group with intact intervertebral disc.

\section{MATERIAL AND METHOD}

Subjects. The subjects with normal radiological evaluation were selected for the study. A total of 74 subjects participated in MRI including 37 (20 males, 17 females) patients who were diagnosed with a lumbar intervertebral disc herniation at the end of 1-month clinic duration (the Patient Group), and 37 (20 males, 17 females) control cases with low back pain only. The control group consisted of 37 people with low back pain but no lumbar intervertebral disc herniation. The Patient Group consisted of 37 patients with lumbar disc herniation but no surgery. The patients and controls were referred from the radiology clinic of Recep Tayyip Erdogan University Education and Research Hospital. Radiological images of the patients were taken from the university hospital. This study was approved by the ethical committee of the University, Turkey.

\section{The Exclusion Criteria}

- Patients who were Moderate and Morbid Obese (Body Mass Index at and above 35).

- Patients who had severe degenerative changes (arthritis) in the hip and knee joint.

- Patients who underwent lumbar intervertebral disc herniation surgery.

- Patients who had severe spinal canal stenosis that accompanied lumbar disc herniation.

- Patients who had more than one lumbar disc herniation.

- Patients who had severe spinal traumas or underwent a different surgical intervention for the spine.
- The clinical duration of patients with intervertebral disc herniation are at least 1 month or longer.

MRI procedure. MRI was performed at $1.5 \mathrm{~T}$ scanner (GE Healthcare - SIGNAArtist, United States). Lumbar anatomical images were acquired in the sagittal and transverse plane using T1/T2-weighted turbo spin-echo images. The following parameters were used for the imaging process; TR/TE: 1000 ms/80s; Flip angle=20 degrees, FOV: 400 x 200; acquisition matrix $=4 \mathrm{~mm} \times 1.5 \mathrm{~mm}$, number of slices $=160$ and slice thickness $=1.0 \mathrm{~mm}$. MR images were used for anatomical measurements and volume estimation.

\section{Anatomical measurements by a universal DICOM Viewer}

Measurements on T1-weighted sagittal plane images (Fig. 1):

-Front and rear height of L1-L5 vertebrae

- Front and rear height of intervertebral space or discs (from T12-L1 to L5-S1)

Measurements on T2-weighted axial plane images (Fig. 1): - Anterior-posterior and transverse diameter of the vertebral body (from L1 to L5)

Volume estimation of LIVD and the vertebral body by the Cavalieri method. The Cavalieri method is based on the pointcounting method that is used for unbiased estimation of the volume of any structure (Gundersen et al., 1999; Cruz-Orive, 2006). Using the Cavalieri Method, an estimate of the volume of a structure of irregular shape and size may be obtained influentially and with known precision (Roberts et al., 1993). The Cavalieri Method has been used for volume estimations in the literature (Nisari et al., 2012; Deg ermenci et al., 2016; Ertekin et al., 2016). The Point-counting Method is based on the Cavalieri Principle. According to this method, the MRIs of a section series $4 \mathrm{~mm}$ thickness were used to estimate the volume of the structure. The films were saved on a computer and the transparent square grid test system with $\mathrm{d}=0.9 \mathrm{~cm}$ between test points was superimposed, randomly covering the entire image frame. The points hitting the structure sectioned surface area were counted for each section and the volume of the brain and substructures was estimated using the modified formula (Eq. 1) for volume estimations of radiological images shown below (Barghouth et al., 2002; Sahin \& Ergur, 2006; Sahin et al., 2007).

$$
V=t\left[\frac{\mathrm{SU} \times d}{\mathrm{SL}}\right]^{2} \times \sum P
$$

Where $t$ is the section thickness, $\mathrm{SU}$ the scale unit of the printed film, $d$ the distance between the test points of the grid, SL the measured length of the scale printed on the film and $\sum \mathrm{p}$ is 


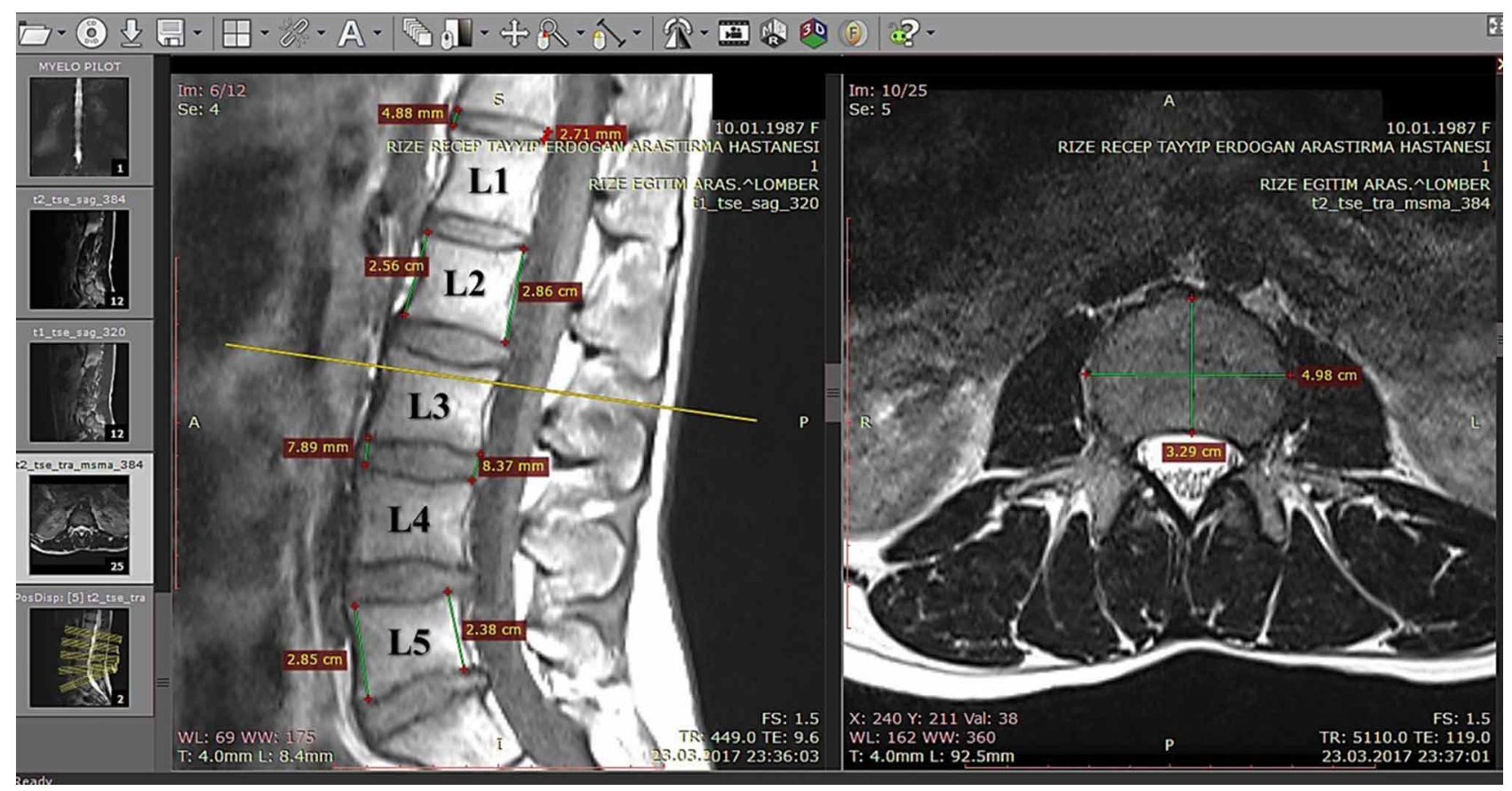

Fig. 1. Anatomical measurements points on sagittal T1 and axial T2 weighted MRI Sections by DICOM viewer.

the total number of points hitting the sectioned cut surface areas of the structure (Mahato, 2013; Wang et al., 2015; Azu et al.; Keskinoz et al., 2016). According to this volumetric technique, a square grid of test points was positioned on each MRI, and all points hitting the structure were counted (Fig. 2).

Statistical analysis: The IBM Statistical Package for the Social Sciences (SPSS) software was used in the statistical

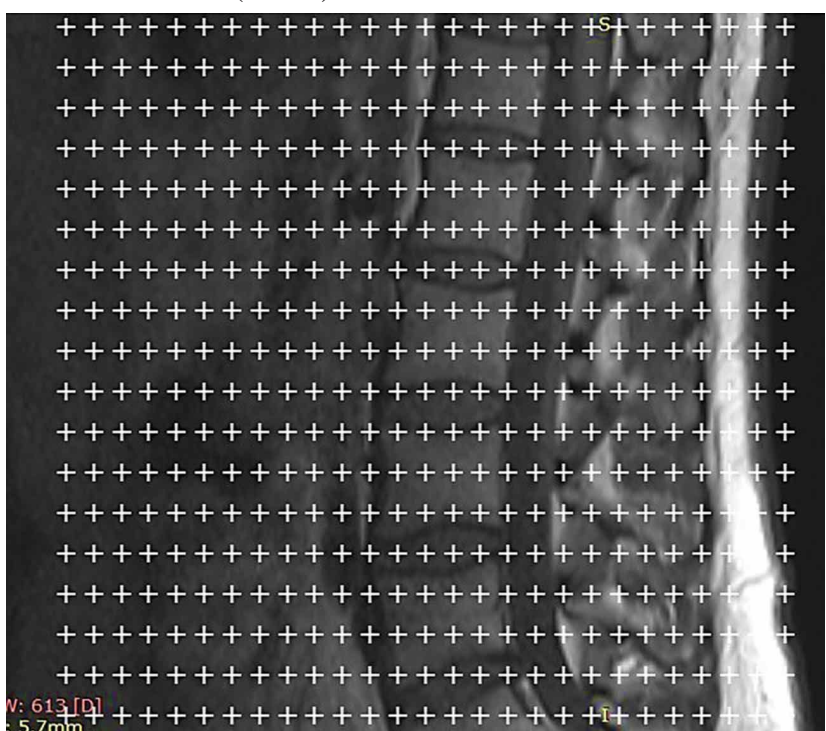

Fig. 2. Lumbar MRI with a point-counting grid superimposed on it for the volume estimation of vertebral body and intervertebral disc space. analysis of the data. The normal distribution of the data was analyzed with the Kolmogorov-Smirnov Test. The Independent t-test was used for the comparisons between the groups. The correlation between the parameters was determined with the Pearson Correlation Test. The statistical significance level was taken as $\mathrm{p}<0.05$. The data were presented as Mean \pm Standard Deviation (mean \pm SD).

\section{RESULTS}

There were L4-5 in 20 patients, L5-S1 in 11, L3-4 in 5 and L2-3 disc herniation in 1 patient. There were disc herniations with extruded or sequestered extending into the spinal canal in all cases. The cases were selected randomly within one year. The intervertebral disc wall of the Group II was intact. The female/male rate was equal in all 2 groups. Group II had only low back pain that spine movements for at least 1 month. The mean age of the groups was evaluated and was determined as 46.59 \pm 12.11 , and Group II was younger with $36.18 \pm 11.42(\mathrm{P}=0.0001)$. The fact that there were younger people in Group II did not prevent our evaluations. The groups' not having the same mean age was considered to facilitate a better understanding of the effect of age in the degenerative process.

Firstly in all groups, front and rear heights and lengths of the vertebral body (corpus) were measured on sagittal MRI 
sections, and transverse widths were also measured on axial MRI sections. The measurements that were obtained for each vertebra are shown in Tables I and II. When Group II and Group I were compared, it was found that the measurements were greater at a significant level in millimeters $(p<0.05)$. No statistically significant differences were detected between Group II and Group I when they were compared with the independent samples $\mathrm{T}$ test $(\mathrm{p}>0.05)$. The anterior-posterior diameters of the L5 vertebral body were greater at a significant level in Group I when compared to Group II $(\mathrm{p}<0.05)$.

Table I. Comparison of height measurements in the sagittal plane of lumbar vertebral body.

\begin{tabular}{lccccc}
\hline Height measurements of & \multicolumn{2}{c}{ Control Group } & \multicolumn{2}{c}{ Patient Group } & P \\
lumbar vertebrae $(\mathbf{c m})$ & Min-Max & A \pm Sd & Min-Max & A \pm Sd & \\
\hline Front height of L1 & $1.87-2.92$ & $2.52 \pm 0.25$ & $2.15-2.89$ & $2.52 \pm 0.18$ & $\mathbf{0 . 9 2 7} *$ \\
Rear height of L1 & $2.07-3.03$ & $2.63 \pm 0.24$ & $1.68-3.12$ & $2.64 \pm 0.26$ & $\mathbf{0 . 8 5 1} *$ \\
Front height of L2 & $2.22-3.13$ & $2.69 \pm 0.24$ & $2.21-3.19$ & $2.68 \pm 0.20$ & $\mathbf{0 . 7 4 2 *}$ \\
Rear height of L2 & $2.21-3.26$ & $2.76 \pm 0.26$ & $2.07-3.18$ & $2.70 \pm 0.23$ & $\mathbf{0 . 2 9 1} *$ \\
Front height of L3 & $2.23-3.20$ & $2.83 \pm 0.23$ & $2.20-3.15$ & $2.81 \pm 0.21$ & $\mathbf{0 . 7 3 9 *}$ \\
Rear height of L3 & $2.26-3.25$ & $2.73 \pm 0.23$ & $2.13-3.07$ & $2.70 \pm 0.24$ & $\mathbf{0 . 6 0 0 *}$ \\
Front height of L4 & $2.32-3.06$ & $2.79 \pm 0.19$ & $2.29-3.08$ & $2.75 \pm 0.19$ & $\mathbf{0 . 3 4 6} *$ \\
Rear height of L4 & $2.27-3.06$ & $2.66 \pm 0.21$ & $2.19-3.15$ & $2.59 \pm 0.22$ & $\mathbf{0 . 1 5 5} *$ \\
Front height of L5 & $2.39-3.33$ & $2.90 \pm 0.21$ & $2.29-3.59$ & $2.84 \pm 0.28$ & $\mathbf{0 . 3 2 7} *$ \\
Rear height of L5 & $1.83-2.77$ & $2.36 \pm 0.22$ & $1.72-2.66$ & $2.35 \pm 0.22$ & $\mathbf{0 . 8 8 7} *$ \\
\hline
\end{tabular}

* Independent t test, $\mathrm{p}>0.05$; There was no statistically significant difference between the groups. A:Average, Sd: Standard deviation

Table II. Comparison of diameter measurements in the axial plane of lumbar vertebral body.

\begin{tabular}{lccccc}
\hline $\begin{array}{l}\text { Vertebral diameter } \\
\text { measurements }(\mathbf{c m})\end{array}$ & \multicolumn{2}{c}{ Control Group } & \multicolumn{2}{c}{ Patient Group } & Pin-Max \\
\hline A-P Dia of L1 & A \pm Sd & Min-Max & A \pm Sd & \\
Tr Dia of L1 & $3.34-3.85$ & $3.19 \pm 0.36$ & $2.67-4.64$ & $3.32 \pm 0.42$ & $\mathbf{0 . 1 4 0 *}$ \\
A-P Dia of L2 & $2.41-4.33$ & $3.40 \pm 0.40$ & $2.77-4.62$ & $3.55 \pm 0.35$ & $\mathbf{0 . 0 9 0 *}$ \\
Tr Dia of L2 & $3.63-5.88$ & $4.68 \pm 0.47$ & $3.82-5.70$ & $4.65 \pm 0.45$ & $\mathbf{0 . 8 1 9 *}$ \\
A-P Dia of L3 & $2.85-4.26$ & $3.55 \pm 0.34$ & $3.10-4.20$ & $3.69 \pm 0.32$ & $\mathbf{0 . 0 7 9 *}$ \\
Tr Dia of L3 & $3.72-5.99$ & $4.80 \pm 0.44$ & $3.97-5.51$ & $4.82 \pm 0.40$ & $\mathbf{0 . 8 4 4}$ \\
A-P Dia of L4 & $2.85-4.58$ & $3.53 \pm 0.34$ & $3.09-4.57$ & $3.71 \pm 0.35$ & $\mathbf{0 . 0 3 2 * *}$ \\
Tr Dia of L4 & $4.12-5.82$ & $4.75 \pm 0.39$ & $4.07-5.89$ & $4.77 \pm 0.43$ & $\mathbf{0 . 8 3 6 *}$ \\
A-P Dia of L5 & $2.91-4.53$ & $3.51 \pm 0.38$ & $3.08-4.40$ & $3.73 \pm 0.32$ & $\mathbf{0 . 0 0 7 * *}$ \\
Tr Dia of L5 & $3.60-6.58$ & $4.84 \pm 0.59$ & $4.12-5.76$ & $4.86 \pm 0.46$ & $\mathbf{0 . 8 1 9 *}$ \\
\hline
\end{tabular}

* Independent $t$ test, $\mathrm{p}>0.05$; There was no statistically significant difference between the groups; ** Independent $\mathrm{t}$ test, $\mathrm{p}<0.05$. There was a statistically significant difference between the groups). A-P Dia: Anterior-Posterior Diameter, Tr: Transverse, A:Average, Sd: Standard deviation

Table III. Comparison of height of the lumbar intervertebral discs in sagittal plane.

\begin{tabular}{lccccc}
\hline Height measurements of & \multicolumn{2}{c}{ Control Group } & \multicolumn{2}{c}{ Patient Group } & \multirow{2}{*}{ P } \\
intervertebral discs $(\mathbf{c m})$ & Min-Max & A \pm Sd & Min-Max & A \pm Sd & \\
\hline Front height of T12-L1 & $0.26-0.80$ & $0.57 \pm 0.13$ & $0.41-1.00$ & $0.65 \pm 0.15$ & $\mathbf{0 . 0 2 7} * *$ \\
Rear height of T12-L1 & $0.24-0.85$ & $0.45 \pm 0.13$ & $0.25-1.09$ & $0.44 \pm 0.15$ & $\mathbf{0 . 7 5 3 *}$ \\
Front height of L1-L2 & $0.29-1.10$ & $0.66 \pm 0.19$ & $0.34-1.13$ & $0.73 \pm 0.19$ & $\mathbf{0 . 1 1 7} *$ \\
Rear height of L1-L2 & $0.27-0.80$ & $0.47 \pm 0.13$ & $0.10-0.71$ & $0.43 \pm 0.12$ & $\mathbf{0 . 1 1 0} *$ \\
Front height of L2-L3 & $0.41-1.01$ & $0.79 \pm 0.17$ & $0.35-1.35$ & $0.85 \pm 0.20$ & $\mathbf{0 . 1 5 0} *$ \\
Rear height of L2-L3 & $0.28-0.82$ & $0.54 \pm 0.14$ & $0.32-0.79$ & $0.48 \pm 0.11$ & $\mathbf{0 . 0 5 8}$ \\
Front height of L3-L4 & $0.40-1.43$ & $0.85 \pm 0.23$ & $0.49-1.41$ & $0.94 \pm 0.25$ & $\mathbf{0 . 1 4 6} *$ \\
Rear height of L3-L4 & $0.17-0.92$ & $0.60 \pm 0.20$ & $0.30-0.82$ & $0.56 \pm 0.13$ & $\mathbf{0 . 2 6 3 *}$ \\
Front height of L4-L5 & $0.55-1.77$ & $1.05 \pm 0.26$ & $0.37-1.56$ & $0.98 \pm 0.29$ & $\mathbf{0 . 2 9 8} *$ \\
Rear height of L4-L5 & $0.26-0.89$ & $0.59 \pm 0.15$ & $0.16-0.94$ & $0.54 \pm 0.19$ & $\mathbf{0 . 3 1 4 *}$ \\
Front height of L5-S1 & $0.36-2.23$ & $1.12 \pm 0.31$ & $0.31-1.89$ & $1.15 \pm 0.35$ & $\mathbf{0 . 6 7 7 *}$ \\
Rear height of L5-S1 & $0.26-0.81$ & $0.52 \pm 0.14$ & $0.17-0.94$ & $0.52 \pm 0.19$ & $\mathbf{0 . 9 9 2 *}$ \\
\hline
\end{tabular}

* Independent $\mathrm{t}$ test, $\mathrm{p}>0.05$; There was no statistically significant difference between the groups. ** Independent $\mathrm{t}$ test, $\mathrm{p}<0.05$; There was a statistically significant difference between the groups). A:Average, Sd: Standard deviation. 
As of the Th12-L1 level, the volumes of the lumbar intervertebral discs and the posterior and anterior heights of the L5-S1 disc were measured. The height measurements are given in Table III. The intervertebral disc measurements were smaller at a significant level compared to Group II ( $p<0.05)$. The significant reduction in the volume of all discs in the measurements in Group I is consistent with the deterioration of the intervertebral disc. No statistically significant differences were detected between Group II and Group I according to the independent samples $\mathrm{T}$ test $(\mathrm{p}>0.05)$. The comparison of the vertebral body and intervertebral disc volume values between the groups is given in Table IV.
In addition to these, the Pearson Correlation Test was applied to investigate the existence of a statistical correlation between the changes in the age in the groups and the anterior and posterior heights of the intervertebral disc and vertebral body. No statistically significant correlations were detected between age and discs in terms of the affected side of the height of the disc ( $>0.05)$. In both patient groups that consisted of different ages, the anterior and posterior heights of the intervertebral discs were found to be statistically close. It was determined that only the anterior-posterior diameter of the L5 vertebral body and the transverse diameter of the L5 vertebral body increased $(\mathrm{p}<0.05)$. The correlation is given in Table $\mathrm{V}$.

Table IV. Comparison of lumbar vertebral body and intervertebral disc volumes in both groups.

\begin{tabular}{|c|c|c|c|c|c|}
\hline \multirow{2}{*}{$\begin{array}{l}\text { Vertebral body and } \\
\text { intervertebral disc } \\
\text { volumes }\left(\mathrm{cm}^{3}\right)\end{array}$} & \multicolumn{2}{|c|}{ Control Group } & \multicolumn{2}{|c|}{ Patient Group } & \multirow[t]{2}{*}{$\mathbf{P}$} \\
\hline & Min-Max & $\mathbf{A} \pm$ Sd & Min-Max & $\mathbf{A} \pm$ Sd & \\
\hline Volume of L1 & $19.44-46.66$ & $28.12 \pm 4.63$ & $18.31-35.00$ & $27.82 \pm 4.40$ & 0.771 \\
\hline Volume of L2 & $22.32-50.54$ & $30.92 \pm 4.62$ & $22.65-43.01$ & $33.38 \pm 5.10$ & 0.033* \\
\hline Volume of L3 & $23.33-54.53$ & $35.86 \pm 5.49$ & $25.71-54.72$ & $36.42 \pm 6.33$ & 0.687 \\
\hline Volume of L4 & $26.83-62.21$ & $36.35 \pm 6.13$ & $23.32-61.63$ & $37.68 \pm 8.41$ & 0.440 \\
\hline Volume of L5 & $26.17-60.91$ & $35.68 \pm 5.94$ & $23.04-56.45$ & $34.46 \pm 6.73$ & 0.410 \\
\hline IVDV of T12-L1 & $5.51-20.74$ & $11.30 \pm 3.43$ & $4.49-14.40$ & $8.87 \pm 2.09$ & $0.000 *$ \\
\hline IVDV of L1-L2 & $6.08-29.81$ & $13.95 \pm 4.28$ & $6.75-17.50$ & $11.62 \pm 2.49$ & $0.005 *$ \\
\hline IVDV of L2-L3 & 7.59-25.92 & $17.01 \pm 3.71$ & $9.54-24.19$ & $14.13 \pm 3.16$ & $0.001 *$ \\
\hline IVDV of L3-L4 & $11.21-29.81$ & $19.81 \pm 4.67$ & $5.43-23.98$ & $15.47 \pm 4.26$ & $0.000 *$ \\
\hline IVDV of L4-L5 & $10.56-26.58$ & $20.19 \pm 4.31$ & $8.40-22.50$ & $14.46 \pm 3.59$ & $0.000 *$ \\
\hline IVDV of L5-S1 & $6.43-30.12$ & $15.69 \pm 4.35$ & $4.20-20.67$ & $12.26 \pm 3.76$ & 0.001* \\
\hline
\end{tabular}

* Independent $\mathrm{t}$ test, $\mathrm{p}<0.05$. There was a statistically significant difference between the groups.

Table V. Investigation of correlation between lumbar vertebral body height with diameters and age changes.

\begin{tabular}{lcc}
\hline Vertebral height and diameters & \multicolumn{2}{c}{ Age } \\
\hline Front height of $\mathbf{L 1}$ & $\mathbf{r}$ & $\mathbf{P}$ \\
\hline Rear height of $\mathbf{L 1}$ & -0.030 & 0.797 \\
A-P dia of $\mathbf{L 1}$ & -.089 & 0.452 \\
Tr dia of $\mathbf{L 1}$ & 0.132 & 0.262 \\
Front height of $\mathbf{L 2}$ & -0.006 & 0.962 \\
Rear height of $\mathbf{L 2}$ & -0.088 & 0.456 \\
A-P dia of $\mathbf{L 2}$ & -0.098 & 0.408 \\
Tr dia of $\mathbf{L 2}$ & 0.070 & 0.553 \\
Front height of $\mathbf{L 3}$ & 0.055 & 0.640 \\
Rear height of $\mathbf{L 3}$ & -0.193 & 0.100 \\
A-P dia of $\mathbf{L 3}$ & -0.033 & 0.781 \\
Tr dia of $\mathbf{L 3}$ & 0.168 & 0.151 \\
Front height of $\mathbf{L 4}$ & 0.098 & 0.408 \\
Rear height of $\mathbf{L 4}$ & -0.090 & 0.444 \\
A-P dia of $\mathbf{L 4}$ & -0.160 & 0.173 \\
Tr dia of $\mathbf{L 4}$ & 0.186 & 0.113 \\
Front height of $\mathbf{L 5}$ & 0.025 & 0.834 \\
Rear height of $\mathbf{L 5}$ & -0.136 & 0.247 \\
A-P dia of $\mathbf{L 5}$ & -0.060 & 0.613 \\
Tr dia of $\mathbf{L 5}$ & 0.257 & $\mathbf{0 . 0 2 7}$ \\
\hline
\end{tabular}

*Pearson Correlation Test, $\mathrm{p}<0.05$. A-P dia: Anterior-Posterior diameter, Tr dia: Transverse diameter.
In addition, when the correlation between vertebral body and intervertebral disc volumes and age was considered, it was determined that the volumes of L2, L4, and L5 vertebral body increased with increasing age (Pearson Correlation Test, $\mathrm{p}<0.05)$. This relation is shown in Table VI.

Table VI. Investigation of correlation between lumbar vertebral body with intervertebral disc volume and age.

\begin{tabular}{lcc}
\hline Volume & \multicolumn{2}{c}{ Age } \\
\hline Volume of L1 & r & P \\
Volume of L2 & 0.127 & 0.281 \\
Volume of L3 & 0.26 & $\mathbf{0 . 0 2 5}$ \\
Volume of L4 & 0.076 & 0.522 \\
Volume of L5 & 0.349 & $\mathbf{0 . 0 0 2} *$ \\
IVD of T12-L1 & 0.299 & $\mathbf{0 . 0 1 0}$ \\
IVD of L1-L2 & -0.039 & 0.742 \\
IVD of L2-L3 & -0.058 & 0.626 \\
IVD of L3-L4 & -0.042 & 0.720 \\
IVD of L4-L5 & 0.043 & 0.718 \\
IVD of L5-S1 & -0.224 & 0.055 \\
\hline
\end{tabular}

*Pearson Correlation Test, $\mathrm{p}<0.05$, r: Pearson correlation coefficient, If the value is closer to 1 or -1 , there is the strong linear correlation. 


\section{DISCUSSION}

Intervertebral discs (IDs) and vertebrae have an important role in posture, biomechanics, and balancing of the body. With technological advances, imaging is carried out with MRI devices that have much higher image quality. In this way, the anatomical changes that occur in the human body with furthering age can be evaluated better. For this purpose, it was investigated how and to what extent the deterioration of IDs on the lumbar vertebrae anatomy, which is the most important part of our body carrying our weight, occurred. Anatomical and morphological features of IDs lead to changes in the composition of IDs (i.e. fluid loss, cell volume decrease, diminished proteoglycan content) that is often caused by volumetric decreases, intervertebral disc degeneration, herniations, infection, trauma and aging (Tang et al., 2016; James et al.). Thus, the height and size of IDs are commonly used to diagnose and evaluate the pathologies of the spine. The degree of disc degeneration has been commonly assessed by the disc height decrease rather than by changes in signal intensity in the nucleus pulposus on MRI (Roberts \& Johnson, 1999; Suthar et al., 2015; Topuz et al., 2016).

Different from previous morphometric anatomy studies, in our study, the purpose was to show how much the impairment of spine stability affected not only the intervertebral disc tissue but also the vertebral body. For this purpose, as Lee et al. (2017), and Karabekir et al., did in their studies, the morphometric measurements were made by using the same measurement points (Hong et al., 2010; Tang et al.; Lee et al.). In the study of Lee et al., the morphometric measurements were made by using the lateral-spine X-ray images. Hong et al. made the same measurements by using lumbar spine MRI images. The findings of both studies agreed numerically with our findings. The study of Lee et al. was the one that had the closest methodology to ours. A comparative evaluation was made in a group of 20-25 year-old patients who only had a disc herniation and disc degeneration for the L4-5 intervertebral disc (Lee et al.). In the group that did not have disc herniation $(\mathrm{n}=198)$, front height of the L4-5 disc was $19.2 \pm 2.9 \mathrm{~mm}$, the rear height was $10.9 \pm 2.0 \mathrm{~mm}$, midpoint was $14.9 \pm 2.1$ $\mathrm{mm}$, and the antero-posterior diameter was measured as $41.4 \pm 4.0 \mathrm{~mm}$. Front height of the L4 vertebral body was found as $31.0 \pm 2.3 \mathrm{~mm}$. The measurement values are slightly lower in the disc herniation group. In our study, front height of the L4-5 disc was found as $10.5 \pm 2.6 \mathrm{~mm}$, and the rear height was $5.8 \pm 1.5 \mathrm{~mm}$ in the Control Group $(\mathrm{n}=37)$. Front height of the L4 vertebral body was found as $27.9 \pm 1.9 \mathrm{~mm}$. Anterior-posterior diameter of the L4 vertebral body was $35.3 \pm 3.4 \mathrm{~mm}$. Our measurements were slightly lower in the group that had a disc herniation and were close to Lee's measurements. Different from the study of Lee, the intervertebral disc medium height was not measured; however, the intervertebral disc volumes were calculated with the Cavaliere Method on the lumbar spine. In addition, our measurements were parallel to the results of Mirab et al. (2017). The anterior height of the intervertebral disc was found to be more than the posterior height, which is similar to our results (Mirab et al.). The posterior height of the intervertebral disc being more than the anterior height in millimeters may be the result or the cause of the formation of the lordotic posture of the lumbar spine.

The morphometric studies about this subject in the literature have generally focused on the change of intervertebral disc. In addition, the level of the degeneration of the intervertebral disc was found to be proportional with the loss of height. On the other hand in our study, we focused on whether there was any change in the vertebral body together with intervertebral disc. In fact, the formation of intervertebral disc herniation is the result of the process, which is called degeneration, the biomechanical changes, and aging (Mirab et al.; Wang et al., 2019). It is expected that some changes occur in the vertebral body during this process of change. A definition of intervertebral disc degeneration has not been uniformly applied, although it is well known that disc tissue shows progressive morphological, structural, histological, biochemical and functional changes with aging (Urban \& Roberts, 2003; Adams \& Roughley, 2006). Based on the findings of our study, it is understood that that disc structure does not deteriorate acutely immediately in the process of intervertebral disc herniation. It is understood that the intervertebral disc herniation is affected by the change in the vertebral corpus depending on the changing center of gravity and the load distribution after the deterioration stage of the disc structure.

In the study conducted by Akeda et al. (2015), it was concluded that the lumbar disc height of the elderly inhabitants of a mountain village gradually decreased over time, and the rate of change in disc height did not differ significantly among disc levels. In this respect, although there were no differences between disc levels, it was shown that there was a decrease in lumbar intervertebral disc heights in women, in those who had osteoarthritis of the knee joint, and especially in the elderly who had chronic low back pain (Akeda et al.). In our study group, since there were no patients at advanced ages, no correlations were detected between the increase in age and decrease in intervertebral disc height. In addition, the patients who had hip joint pathology and obesity (patients who had moderate and morbid obesity), which could affect lumbar biomechanics, 
were excluded in both groups. However, in our radiological observations, it was determined that the heights of IDs, especially at the midpoint of IDs, were decreased. In addition to these, our study showed statistically that the anterior and posterior heights of the disc are generally preserved even in the patient group in early period after clinical signs. The progression of disc degeneration is one of the underlying pathologies of the degenerative lumbar diseases commonly seen in the elderly population (Akeda et al.; Lee et al.; Demir et al., 2018).

There is still a need for evidence that will be reported with more extensive epidemiological investigations about IDs degeneration. To contribute to the understanding of the relevant pathology, it is also necessary to evaluate the vertebral bone structure. In this study, the intervertebral disc degeneration and anatomical changes in the vertebral body were evaluated. In both study groups, the L2, L4 and L5 vertebral body volumes increased in correlation with increasing age. This finding has evaluated as a long-term result of the decrease in the height of IDs. In addition, when the anterior-posterior diameters of the L5 vertebral body of Group I were compared with Group II, it was determined that these diameters were greater at a significant level in the Patient Group. This result proves that the formation of intervertebral disc herniation occurs as a result of a degenerative process. The vertebral body has adapted itself to the changes as a result of the effects of biomechanical forces and to the load it carries by expanding its surface (Roussouly \& Pinheiro-Franco, 2011).

No statistically significant differences were detected between Group I and II in terms of anterior and posterior heights of the intervertebral disc. However, there was a statistically significant correlation between age changes and intervertebral disc volumes. The reason for this was evaluated as the loss or decrease in the height in the middle of the intervertebral disc.

Limitations of the study: There are several limitations to this study. The mean age of the groups included in the study was not the same; however, it was necessary to understand the biomechanical change in the cases that had a disc herniation. In addition, the further mean age of the patients that had a lumbar intervertebral disc herniation, and the mean age of the patients that had mechanical back pain who underwent MRI being smaller than the disc herniation group caused this. The series of patients in whom measurements will be made can be expanded to include older ages. To evaluate the biomechanical stress on the lumbar vertebrae of the patients who are included in measurements in a more unbiased manner, it was considered that the weights of the patients could be added as a separate parameter in our future studies. In addition, there are patients with age-related degenerative change in group 1 . However, it is desirable to prove that disc herniation occurs at the end of this process.

\section{CONCLUSION}

In the present study, it was concluded that the L5 vertebral body received partially less degeneration in the Control Group. It was observed that the intervertebral disc received more height losses in the Patient Group. In light of all these findings, it may be argued that intervertebral disc tissue protects against degeneration in the lower lumbar vertebral body. There is no linear correlation between age increase and decrease in intervertebral disc height. In addition, we believe that this study is an objective morphometric and stereological assessment of the effect the intervertebral disc herniation affecting spine biomechanics in the early period. At least, we can summarize this situation as follows: a chicken and egg situation. Which came first the chicken or the egg? Which degenerates initially? Is it vertebrae or intervertebral disc on the spine? We think that both together.

KÖKSAL, V.; AVNIOG`LU, S. \& ATAY, E. ¿Existe algún efecto de la hernia de disco intervertebral en la columna lumbar en el período temprano? Un estudio morfométrico y estereológico. Int. J. Morphol., 38(2):374-381, 2020.

RESUMEN: La degeneración del disco intervertebral lumbar y de otros elementos de la columna vertebral son un resultado inevitable del envejecimiento. Sin embargo, no se observa el mismo grado de degeneración en cada individuo. En el presente estudio, el objetivo era comparar los cambios morfométricos en la columna lumbar con o sin hernia de disco intervertebral en el período temprano. El grupo 1 (grupo de pacientes) estaba formado por los pacientes diagnosticados con hernia de disco intervertebral lumbar y que no fueron operados durante al menos un mes. El Grupo 2 ( Grupo de Control) consistió en sujetos que fueron seleccionados al azar, reportaban solamente dolor de espalda, fueron sometidos a una resonancia magnética (MRI) y se determinó un disco intervertebral intacto. Las secciones de resonancia magnética sagital y axial de la columna lumbar se utilizaron para las mediciones y la evaluación estadística. No hubo diferencias estadísticamente significativas entre los volúmenes del disco intervertebral, los volúmenes del cuerpo vertebral y las alturas anterior y posterior del disco intervertebral de los Grupos 1 y 2 (p> 0,05). En términos de longitud anterior-posterior, se determinó que la longitud del cuerpo vertebral L5 era mayor en el grupo de pacientes ( $\mathrm{p}<0,05)$. Se determinó una correlación en términos del aumento en los volúmenes L2, L4 y L5 con el aumento de la edad; sin embargo, no hubo correlaciones estadísticamente significativas entre el aumento de la edad y una disminución en los volúmenes del disco intervertebral. No hubo correlaciones entre el aumento de la edad y la disminución de las alturas de los discos intervertebrales $(p>0,05)$. No hubo relaciones aparentes entre el 
cambio en el cuerpo de la vértebra lumbar y el disco intervertebral en el período temprano. Se concluyó que el disco intervertebral intacto podría proteger el cuerpo de la vértebra lumbar inferior de los cambios degenerativos. Aun cuando la formación de la hernia del disco fue reciente, se entiende que el proceso fisiológico o los cambios morfométricos habían comenzado antes.

PALABRAS CLAVE: Envejecimiento; Dolor de espalda; Degeneración; Disco intravertebral; Lumbar; Morfometría; Estereología; Cuerpo vertebral.

\section{REFERENCES}

Adams, M. A. \& Roughley, P. J. What is intervertebral disc degeneration, and what causes it? Spine (Phila Pa 1976), 31(18):2151-61, 2006.

Akeda, K.; Yamada, T.; Inoue, N.; Nishimura, A. \& Sudo, A. Risk factors for lumbar intervertebral disc height narrowing: a population-based longitudinal study in the elderly. BMC Musculoskelet. Disord., 16:344, 2015.

Altinel, L.; Köse, K. C.; Ergan, V.; Is sik, C.; Aksoy, Y.; Ozdemir, A.; Toprak, D. \& Dogan, N. The prevalence of low back pain and risk factors among adult population in Afyon Region, Turkey. Acta Orthop. Traumatol. Turc., 42(5):328-33, 2008.

Atta-Alla, E. S. S.; Saab, I. M.; El Shishtawy, M. \& Hassan, K. H. Morphometric study of the lumbosacral spine and some of its related angles in Lebanese adult females. Ital. J. Anat. Embryol., 119(2):92-105, 2014.

Azu, O. O.; Komolafe, O. A.; Ofusori, D. A.; Ajayi, S. A.; Naidu, E. C. S. \& Abiodun, A. A. Morphometric Study of Lumbar Vertebrae in Adult South African Subjects. Int. J. Morphol., 34(4):1345-51, 2016.

Barghouth, G.; Prior, J. O.; Lepori, D.; Duvoisin, B.; Schnyder, P. \& Gudinchet, F. Paranasal sinuses in children: size evaluation of maxillary, sphenoid, and frontal sinuses by magnetic resonance imaging and proposal of volume index percentile curves. Eur. Radiol., 12(6):1451-8, 2002.

Barrera, M. C.; Alústiza, J. M.; Gervás, C.; Recondo, J. A.; Villanúa, J. A. \& Salvador, E. Post-operative lumbar spine: Comparative study of TSE T2 and turbo-FLAIR sequences vs contrast-enhanced SE T1. Clin. Radiol., 56(2):133-7, 2001

Blanchette, M. A.; Stochkendahl, M. J.; Borges Da Silva, R.; Boruff, J.; Harrison, P. \& Bussières, A. Effectiveness and economic evaluation of chiropractic care for the treatment of low back pain: a systematic review of pragmatic studies. PloS One, 11(8):e0160037, 2016.

Cruz-Orive, L. M. A general variance predictor for Cavalieri slices. J. Microsc., 222(Pt. 3):158-65, 2006

Degermenci, M.; Ertekin T, Ülger, H.; Acer, N. \& Cos $_{s}$ kun, A. The age-related development of maxillary sinus in children. J. Craniofac. Surg., 27(1):e3844, 2016.

Demir, M.; Atay, E.; Seringeç, N.; Yoldas, , A.; Çiçek, M.; Ertog rul, R. \& Güneri, B. Intervertebral disc heights and concavity index of the lumbar spine in young healthy adults. Anatomy, 12(1):34-7, 2018.

Ertekin, T.; Deg ermenci, M.; Nisari, M.; Unur, E. \& Cos sun, A. Age-related changes of nasal cavity and conchae volumes and volume fractions in children: a stereological study. Folia Morphol. (Warsz.), 75(1):38-47, 2016.

Gocmen-Mas, N.; Karabekir, H.; Ertekin, T.; Edizer, M.; Canan, Y. \& Duyar, I. Evaluation of lumbar vertebral body and disc: a stereological morphometric study. Int. J. Morphol., 28(3):841-7, 2010.

Gundersen, H. J.; Jensen, E. B.; Kiêu, K. \& Nielsen, J. The efficiency of systematic sampling in stereology--reconsidered. J. Microsc., 193(Pt. 3):199-211, 1999.

Hong, C. H.; Park, J. S.; Jung, K. J. \& Kim, W. J. Measurement of the normal lumbar intervertebral disc space using magnetic resonance imaging. Asian Spine J., 4(1):1-6, 2010.

James, G.; Klyne, D. M.; Millecamps, M.; Stone, L. S. \& Hodges, P. W. ISSLS Prize in Basic science 2019: ISSLS Prize in Basic Science 2019: Physical Activity Attenuates Fibrotic Alterations to the Multifidus Muscle Associated With Intervertebral Disc Degeneration. Eur. Spine J., 28(5):893-904, 2019.

Keskinoz, E. N.; Salbacak, A.; Akin, D.; Kabakci, A. D. A.; Yilmaz, M. T.; Cicekcibasi, A. E. \& Ozbek, O. Morphometric analysis of the inferior vena cava related to lumbar vertebra and the aortic bifurcation on Multidetector Computed Tomography (MDCT). Int. J. Morphol., 34(2):620-7, 2016.

Kim, H. J.; Chung, S.; Kim, S.; Shin, H.; Lee, J.; Kim, S. \& Song, M. Y Influences of trunk muscles on lumbar lordosis and sacral angle. Eur. Spine J., 15(4):409-14, 2006.

Lee, K.; Shin, J. S.; Lee, J.; Lee, Y. J.; Kim, M. R.; Seong, I.; Jun, J.; Park, K. B. \& Ha. I. Lumbar intervertebral disc space height in disc herniation and degeneration patients aged 20 to 25. Int. J. Clin. Exp. Med., 10(4):682836, 2017.

Mahato, N. K. Anatomy of lumbar interspinous ligaments: attachment, thickness, fibre orientation and biomechanical importance. Int. J. Morphol., 31(1):351-5, 2013.

Maher, C.; Underwood, M. \& Buchbinder, R. Non-specific low back pain. Lancet, 389(10070):736-47, 2017.

Mirab, S. M. H.; Barbarestani, M.; Tabatabaei, S. M.; Shahsavari, S. \& Zangi, M. B. M. Measuring dimensions of lumbar intervertebral discs in normal subjects. Anat. Sci., 14(1):3-8, 2017.

Nisari, M.; Ertekin, T.; Ozçelik, O.; Cinar, S.; Doganay, S. \& Acer, N. Stereological evaluation of the volume and volume fraction of newborns brain compartment and brain in magnetic resonance images. Surg. Radiol. Anat., 34(9):825-32, 2012.

Roberts, N.; Cruz-Orive, L. M.; Reid, N. M.; Brodie, D. A.; Bourne, M. \& Edwards, R. H. Unbiased estimation of human body composition by the cavalieri method using magnetic resonance imaging. J. Microsc., 171(Pt. 3):239-53, 1993.

Roberts, S. \& Johnson, W. E. Analysis of aging and degeneration of the human intervertebral disc. Spine (Phila Pa 1976), 24(5):500-1, 1999.

Roussouly, P. \& Pinheiro-Franco, J. L. Biomechanical analysis of the spinopelvic organization and adaptation in pathology. Eur. Spine J., 20(Suppl. 5):609-18, 2011.

Sahin, B.; Acer, N.; Sonmez, O. F.; Emirzeoglu, M.; Basaloglu, H.; Uzun, A. \& Bilgic, S. Comparison of four methods for the estimation of intracranial volume: a gold standard study. Clin. Anat., 20(7):766-73, 2007.

Sahin, B. \& Ergur, H. Assessment of the optimum section thickness for the estimation of liver volume using magnetic resonance images: a stereological gold standard study. Eur. J. Radiol., 57(1):96-101, 2006.

Suthar, P.; Patel, R.; Mehta, C. \& Patel, N. MRI evaluation of lumbar disc degenerative disease. J. Clin. Diagn. Res., 9(4):TC04-9, 2015.

Tang, R.; Gungor, C.; Sesek, R. F.; Foreman, K. B.; Gallagher, S. \& Davis, G. A. Morphometry of the lower lumbar intervertebral discs and endplates: comparative analyses of new MRI data with previous findings. Eur. Spine J., 25(12):4116-31, 2016.

Topuz, K.; Eroglu, A.; Simsek, H.; Atabey, C.; Cetinkal, A. \& Colak, A Demographical aspects of central large lumbar disc herniation. Turk. Neurosurg., 26(1):111-8, 2016.

Urban, J. P. G. \& Roberts, S. Degeneration of the intervertebral disc. Arthritis Res. Ther., 5(3):120-30, 2003.

Wang, F.; Zhang, C.; Sinkemani, A.; Shi, R.; Xie, Z. Y.; Chen, L.; Mao, L. \& Wu, X. T. A Histocytological and Radiological Overview of the Natural History of Intervertebral Disk: From Embryonic Formation to Age-Related Degeneration. Eur. Spine J., 28(4):633-48, 2019.

Wang, Y.; Liu, T.; Song, L. S.; Zhang, Z. X.; Li, Y. Q. \& Lu, L. J. Anatomical Characteristics of Deer and Sheep Lumbar Spines: Comparison to the Human Lumbar Spine. Int. J. Morphol., 33(1):105-12, 2015.

\section{Corresponding author: \\ Dr. Vaner Köksal \\ University of Health Sciences \\ Department of Neurosurgery \\ Samsun \\ TURKEY}

\section{Email: vanerkoksal@hotmail.com vaner.koksal@sbu.edu.tr}

Received: 16-07-2019

Accepted: 13-09-2019 